\title{
Microstructure and Mechanical Properties of Ti-6Al-4V Manufactured by Selective Laser Melting after Stress Relieving, Hot Isostatic Pressing Treatment, and Post-Heat Treatment
}

\author{
Naeem Eshawish, Savko Malinov, Wei Sha, and Patrick Walls
}

Submitted: 17 December 2020 / Revised: 21 March 2021 / Accepted: 30 March 2021 / Published online: 15 April 2021

\begin{abstract}
Additive manufacturing (AM) is defined as a technology performed for tooling applications. It is used for manufacturing tools that have complex shapes and figures. In this study, an extensively applied Ti-6Al-4V alloy was made using the selective laser melting method. Post-production heat treatments were applied to decrease thermal stresses and to enhance the mechanical properties and the microstructure. The study investigates the fatigue mechanical properties, microstructure, hardness, and porosity of the AM Ti-6Al-4V after stress relieving (SR) and after SR followed by hot isostatic pressing (HIP). The samples' upper and lower parts were independently examined to determine the effects of thermal conditions and the heat treatment of the microstructure. The microstructures were examined through optical microscopy, scanning electron microscopy and $x$-ray diffraction methods. The mechanical properties were investigated through microhardness testing, alongside assessment by fatigue testing at room temperature. The findings demonstrated that the microstructure after $\mathrm{SR}$ at $704{ }^{\circ} \mathrm{C}$ for $2 \mathrm{~h}$ is $100 \%$ fine martensitic $\alpha^{\prime}-\mathrm{Ti}$, with a microhardness value of $408 \mathrm{HV}$. Air and furnace cooled samples have a more homogenous structure and are characterised by mixture $(\alpha+\beta)$ with microhardness values of 382 and $356 \mathrm{HV}$, respectively. After HIP at $920{ }^{\circ} \mathrm{C}$ and $100 \mathrm{MPa}$ for $2 \mathrm{~h}$ was applied, the martensite was converted into a lamellar $(\alpha+\beta)$ microstructure, whereby the $\alpha$ phase is presented as fine needles situated among the $\beta$ ridges in the microstructure, with the existence of the prior $\beta$ grain boundary.
\end{abstract}

Keywords cooling rate, martensitic, selective laser melting, Ti-6Al-4V

\section{Introduction}

Among the newly developed additive manufacturing processes (AM) which emerged during the late 1980s and early 1990s was the selective laser melting (SLM) technique which can be applied to most non-volatile metals. However, its benefit is best realised when applied to metals that are not easily manufactured through utilising other techniques (Ref 1). Titanium alloys are one such group, possessing an array of exceptional properties, comprising high fracture toughness,

This invited article is part of a special topical focus in the Journal of Materials Engineering and Performance on Additive Manufacturing. The issue was organized by Dr. William Frazier, Pilgrim Consulting, LLC; Mr. Rick Russell, NASA; Dr. Yan Lu, NIST; Dr. Brandon D. Ribic, America Makes; and Caroline Vail, NSWC Carderock.

Naeem Eshawish and Savko Malinov, School of Mechanical and Aerospace Engineering, Queen's University Belfast, Belfast BT7 1NN, United Kingdom; Wei Sha, School of Natural and Built Environment, Queen's University Belfast, Belfast BT7 1NN, United Kingdom; and Patrick Walls, Laser Prototypes Europe, 4 Prince Regent Road, Belfast BT5 6QR, United Kingdom. Contact e-mails: neshawish01@qub.ac.uk, s.malinov@qub.ac.uk, w.sha@qub.ac.uk, and patrick@laserproto.com. outstanding strength-to-weight ratios along with corrosion resistance (Ref 2). The high cost and poor machinability of Ti-6Al-4V utilising conventional processing methods limits its more extensive application. Moreover, titanium alloy production using traditional processing tools results in high energy consumption and extensive material waste. Consequently, researchers are studying methods for processing titanium alloys using non-traditional technologies, such as additive manufacturing technologies. SLM powder AM process which delivers greater benefits compared to traditionally applied production techniques, by decreasing the number of production steps, offering near-net-shape production combines improved level of flexibility and elevated material use efficiency (Ref 3, 4). Nonetheless, the unique conditions required for the SLM process cause certain problems, including but not limited to large thermal gradients emerging during the process, due to the limited interaction time and the highly localised heat input resulting in the build-up of thermal residual stresses. The rapid solidification causes the appearance of non-equilibrium phases and the segregation phenomenon. Additionally, the non-optimal scan parameters may give rise to melt pool instabilities during the process, resulting in higher surface roughness and increased porosity (Ref 1). The SLM Ti-6Al-4V alloy microstructure differs from others produced by utilising conventional techniques. The tiny-melt pool cooling rate that is produced by SLM is thought to be within the range of $10^{3}-10^{5} \mathrm{~K} / \mathrm{s}$, thus exceeding the crucial cooling rate of $410 \mathrm{~K} / \mathrm{s}$ that is necessary for martensitic transformation ( $\beta$ to $\alpha^{\prime}$ ) in Ti-6Al-4V. Consequently, Ti-6Al-4V manufactured by SLM typically consists of acicular $\alpha^{\prime}$ martensite rather than equilibrium $\alpha$ and $\beta$ phases. 
This microstructure usually has high strengths yet low ductility (Ref 5,6). Thus, for optimal building conditions, great effort has now been exerted to comprehend the effect of the process parameters on the mechanical properties and microstructures. Nevertheless, better ductility with strength reduction is noted for SLM-fabricated Ti-6Al-4V, following successive heat treatments involving the transformation of the non-equilibrium phase (acicular $\alpha$ ' martensite) into a near-equilibrium phase (lamellar $\alpha+\beta)(\operatorname{Ref} 7)$. The common heat treatments primarily consist of SR annealing, HIP and two-stage treatment with solution followed by ageing (Ref 8,9$)$. For example, prior studies demonstrated that the HIPed Ti-6Al-4V alloy processed by SLM appears to be more competitive compared with those of wrought material. Moreover, preheating of the build platform can assist with minimising thermal gradients. Therefore, they produce a more controlled cooling, helping to control as-built mechanical properties. Ali et al. (Ref 10, 11) utilised a greater bed preheating temperature; they established that it is possible to eliminate the in-built residual stresses and improve ductility with preheating of the base-plate to $570{ }^{\circ} \mathrm{C}$.

Most research and development on Ti-6Al-4V fabricated by SLM has focused on the microstructure of the as-built samples and adjustment of the process parameters to increase the quality of products (Ref 12, 13). Meanwhile, others have gone further by applying only one stage of heat treatment at different temperatures on the as-built samples, in order to optimise the mechanical properties (Ref 14). This work aims to understand the effect of a combined post-heat treatment-including stress relief, $\alpha+\beta$ annealing, $\beta$ annealing and HIP treatment - as well as cooling rates on the mechanical properties and microstructure of the vertically and horizontally built Ti-6Al-4V specimens by SLM.

\section{Material and Methods}

The experimental material used comprises of Ti-6Al-4V ELI alloy powder with reduced content of interstitial elements. An SLM technique by EOS M290 machine was used to manufacture the specimens. A Yb fibre laser unit was operated by the EOS M290 system with a wavelength of $1075 \mathrm{~nm}$, supplying maximum power output of $400 \mathrm{~W}$ (Ref 15). The building chamber of the EOS M290 machine was filled with argon gas to avoid titanium powder oxidation. Three different laser power levels were used for melting the powder, namely $370 \mathrm{~W}$ for infill, $340 \mathrm{~W}$ for down skin, and $360 \mathrm{~W}$ for up skin. Three different laser power levels were used at different locations, to build the same sample. About $80 \mu \mathrm{m}$ spot diameter, $0.02 \mathrm{~mm}$ overlap stripe, and $30 \mu \mathrm{m}$ layer thicknesses were utilised as manufacturing process parameters. A shell and core concept served as the base for the scan strategy. A raster laser motion first melts the internal part of the layer; this is followed by melting the contour of the layer. A successive layer is then melted after rotating the scanning pattern by a $67^{\circ}$ angle. Twenty-three samples used in this project were $3 \mathrm{D}$ printed in the two directions of horizontal and vertical. The metal alloy powder was spread across the build platform and each layer was traced out by a high-power $\mathrm{CO}_{2}$ laser, which melted and fused the material upon contact. The same process was repeated numerous times until a complete shape of the fatigue specimen was built, with an overall length of $94 \mathrm{~mm}$, grip section width of $19 \mathrm{~mm}$, gauge section width of $7 \mathrm{~mm}$ and thickness of $2.57 \mathrm{~mm}$.

Stress-relieving heat treatment is viewed as a significant step for parts produced by SLM technology, due to substantial thermal-related internal stresses evolving in the parts during the process (Ref 16). For this reason, the specimens were first treated by heat before they were separated from the substrate to avert undesirable deformation. Besides, when it is heated above $427{ }^{\circ} \mathrm{C}$, Ti-6Al-4V will easily oxidise. Accordingly, heat treatments were performed in a vacuum furnace to avert oxidation (Ref 17). In this work, the SR process was carried out in accordance with ASTM F3301, inside a vacuum furnace for $2 \pm 0.25 \mathrm{~h}$ at a temperature of $704 \pm 14{ }^{\circ} \mathrm{C}$. Afterwards, to avoid oxidation and to reduce the development of new residual stresses, the specimens were gradually furnace cooled down to room temperature $\left(25^{\circ} \mathrm{C}\right)$. For microstructure characterisation and testing mechanical properties, eight of SR samples that were built vertically were exposed to extra heat treatment and heated above $\beta$ transus temperature $\left(1015^{\circ} \mathrm{C}\right)$ for $15 \mathrm{~min}$, followed by different cooling rates: furnace-cooling (FC); aircooling (AC); as well as water-cooling (also referred to as water quenching, WQ). The rest were subjected to HIP processing in compliance with ASTM F3301, as illustrated in Fig. 1. The specimens were placed under an inert atmosphere, not less than $100 \pm 5 \mathrm{MPa}$ and $920{ }^{\circ} \mathrm{C}$; they were held at the chosen temperature within $\pm 10^{\circ} \mathrm{C}$ for $120 \pm 30 \mathrm{~min}$, subsequently being cooled down under an inert atmosphere to below $425^{\circ} \mathrm{C}$. Then, the fatigue testing was performed for SR and SR+HIP samples. Table 1 presents the chemical composition of the samples used in this study and analysed by AMG Analytical Services, Rotherham, UK.

Figure 2 exhibits the findings of the fatigue tests which were plotted on a graph that relates to the applied loading and the number of cycles to failure. Among all of the samples, one of the stress-relieved samples has a low number of cycles to failure (indicated with an arrow). A common approach to eliminating porosity-type drawbacks in materials is the material's exposure to increasing pressure at a prominent temperature, namely through hot isostatic pressing, a process which improves the fatigue result (Ref 18). This concurs with the findings presented below. The optimal fatigue result was achieved implementing HIP treatment compared to SR samples owing to reduced porosity.

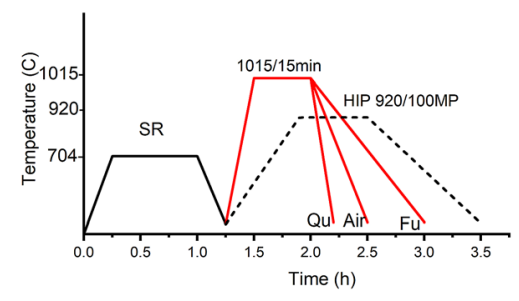

Fig. 1 Schematic illustration of the heat treatment conditions used in this study for $\mathrm{Ti}-6 \mathrm{Al}-4 \mathrm{~V}$ alloy, where $\mathrm{FC}=$ furnace-cooling, $\mathrm{AC}=$ air-cooling, and $\mathrm{WQ}=$ water-cooling 
Table 1 Chemical composition of the samples studied (wt.\%)

SR

$\mathrm{SR}+\mathrm{HIP}$
$\mathrm{Ti}=89.36, \mathrm{Al}=6.4, \mathrm{~V}=3.96, \mathrm{Fe}=0.07, \mathrm{Cr}=0.01, \mathrm{Cu}=0.01$, $\mathrm{O}=0.125, \mathrm{~N}=0.024, \mathrm{C}=0.019, \mathrm{H}=65 \mathrm{ppm}$

$\mathrm{O}=0.119, \mathrm{~N}=0.024, \mathrm{C}=0.015, \mathrm{H}=61 \mathrm{ppm}$

Heavy elements were not analysed in this sample. They are believed to be the same as those in the SR sample

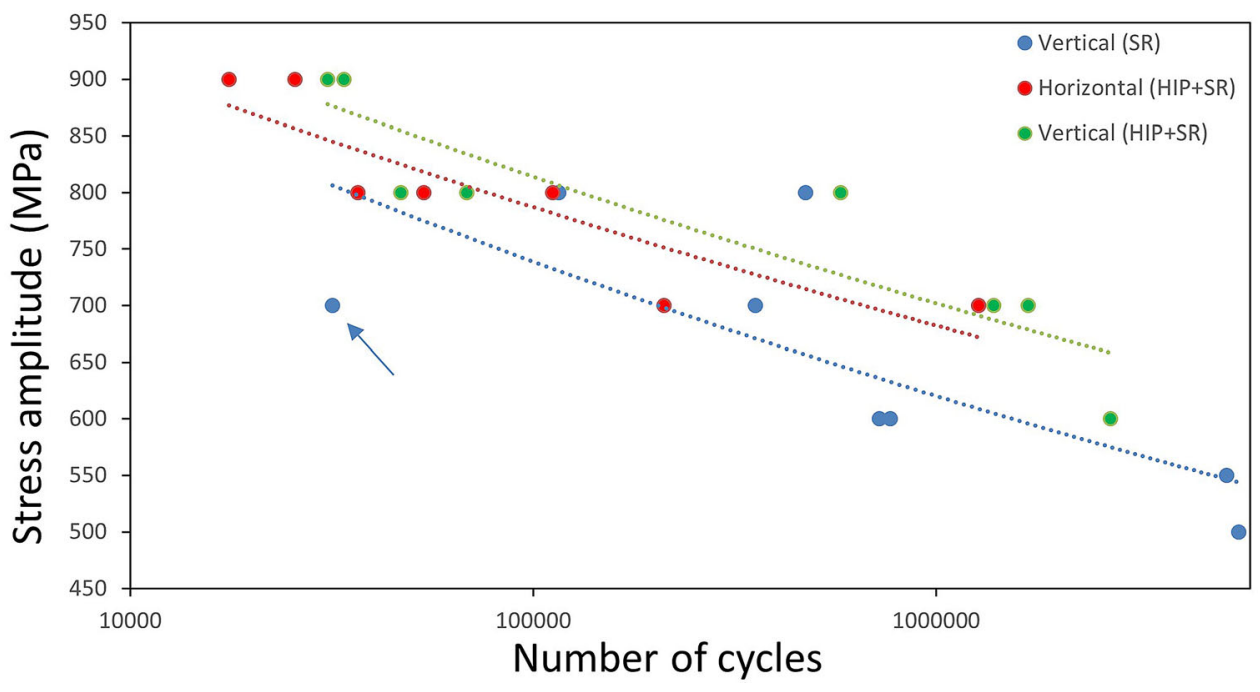

Fig. 2 S-N curve showing fatigue behaviour of different treated Ti-6Al-4V samples

\section{Experimental Procedure}

Operations performed to prepare the metallographic specimen include sectioning, cutting, mounting, planar grinding, rough polishing, final polishing, in addition to etching. First, the specimens were cut by wire electrical discharge machining (EDM) that has a cutting speed of $5 \mathrm{~mm} / \mathrm{min}$. The water was then utilised as a coolant. The samples were first cut into eight pieces, each having a dimension of approximately $10 \times 10 \mathrm{~mm}$. The upper part of each sample was tested independently from the lower part; the test would determine whether or not there was a difference in the microstructure because of the diverse thermal conditions between the two parts within the SLM process. Subsequently, conductive black PolyFast powder was used to mount the samples for subsequent preparation and to hinder the electrostatic charge accumulation at the surface during imaging and analysis by scanning electron microscopy (SEM) and energy-dispersive x-ray spectroscopy (EDS). To eliminate the surface scratches and to conduct a proper microstructure analysis, the samples were ground and then polished to a mirror finish. A Nikon Epiphot optical microscope (OM) was used to obtain images at multiple magnification levels. The porosity was tested and measured in diverse parts of the specimens. Since the etching process will potentially affect the size and depth of the pores (Ref 19), porosity measurement was immediately undertaken after the polishing took place and before displaying the microstructure by etching with Kroll's reagent. The SEM, XRD, and EDS measurement processes were used to evaluate the microstructure evolution of the specimens, characterise the elemental composition, as well as to understand the volume fractions evolution of the $\alpha$ and $\beta$ phases. A Buehler micro indentation hardness tester was used to measure the microhardness. A $0.30 \mathrm{~kg}$ load was applied for $10 \mathrm{~s}$, with a minimum of seven indentations being performed per sample.

\section{Results and Discussion}

\subsection{Porosity Analysis}

Of all the observed SR samples-whether they were in the bottom or top of the specimens - the image analysis did not reveal a significant difference between the samples, where spherical porosity was observed up to $140 \mu \mathrm{m}$ in diameter with approximately $0.31 \pm 0.2 \%$ volume fraction of pore. This result has residual porosity similar to as-built samples of about $0.39 \pm 0.10 \%$ studied by Mezzetta et al. (Ref 20 ). This finding primarily indicates that stress relief during manufacturing has no significant effect on the process of pores formation observed in the examined specimens. On the other hand, higher porosity was noted in the fatigue failed sample with a volume fraction of $0.38 \pm 0.2 \%$, due to the presence of a group of pores of irregular shapes. It is hypothesised that porosity in the SLM parts is usually caused by high volumetric energy density, realised through either increasing the laser power or reducing the scan speed. The result would be a lack of fusion leading to the formation of irregular-shaped of pores whereas the shortage of time for gas mixed with powder to escape from the micromolten pool results in gas that is entrapped during the process; thus, spherical pores. In contrast, the HIP process considerably reduced the porosity level. The HIP process operates by exposing the part to pressure and heat simultaneously. These 
pressures and temperatures permit cracks and voids to be healed within the material, consequently improving the mechanical properties (Ref 21$)$. Nonetheless, some pores were detected ranging in size from 15-21 $\mu \mathrm{m}$, with a volume fraction of $0.20 \pm 0.09 \%$; this was very small compared with the SR samples, as illustrated in Fig. 3.

\subsection{Microstructural Analysis}

The microstructure characterisation process was carried out using an OM Leica DMI3000 M, enabling the obtainment of images at diverse magnification levels. Figure 4 highlights the microstructure of the SR, post-heat treated and HIPed samples. The upper and lower parts of the SR samples were characterised by the microstructure of martensite containing needleshaped features with microhardness value of $408 \mathrm{HV}$ 0.3. This microstructure did not exhibit any significant change compared with those of the as-built samples exemplified in the earlier studies, which presented a very fine acicular $\alpha^{\prime}$ microstructure (Ref 22, 23). The reason for forming the acicular $\alpha$ ' martensitic phase is that the temporary temperature of the Ti64 alloy is exceptionally high under the laser action. This most likely forms the $\beta$-phase, with the diffusionless $\alpha^{\prime}$ phase then being a result of the subsequent rapid cooling process. The cooling rate within SLM processing exceeds $410 \mathrm{~K} / \mathrm{s}$, which is suggested as a martensite $\alpha$ ' formation rate (Ref 24). After being quenched from $1015^{\circ} \mathrm{C} / 15 \mathrm{~min}$, the microstructure also performs an entire formation process of a new $\alpha^{\prime}$ martensite with a somewhat lower microhardness. Both the length and width of the prior $\beta$ grains increase compared with the SR structure; it is now approximately $1.1-1.8 \mu \mathrm{m}$ wide and roughly $0.9-1.2 \mu \mathrm{m}$ for the SR one. This increase is caused by the difference in the cooling rate between the traditional WQ and the SLM process. The air-cooled sample's microstructure consists of a mixture of $\alpha$ phase (displayed as coarse needles) and coarse $\alpha$ phase, which decorated the prior $\beta$ grain boundaries with a microhardness value of $382 \mathrm{HV} 0.3$. Furnace cooling from $1015^{\circ} \mathrm{C}$ results in a coarser microstructure comprised of $\alpha$ (3-5.2 $\mu \mathrm{m})$ and small volume fraction of $\beta(\sim 8.5 \%)$, with a microhardness value of $356 \mathrm{HV} 0.3$. Meanwhile, the SR + HIP specimens which did not experience any additional post-treatment also demonstrated a mixture of $\alpha+\beta$ lamellar microstructure, where the $\alpha$ amount increases with a reduction in the amount of $\beta$ volume fraction to $\sim 6 \%$ following the HIP treatment process. The size of $\alpha$ lamellar after HIP is approximately between 2-5 $\mu \mathrm{m}$, with a microhardness value of $364 \mathrm{HV} 0.3$. This result is similar to that obtained from furnace cooling. Figure 6 presents the EDS spectra and the composition in wt. \% for samples that are heat treated in various regions. The disparity in aluminium and vanadium in dark and white areas is a result of the presence of each within a preferred area, where aluminium stabilises the $\alpha$ phase (white), while vanadium stabilises the $\beta$ phase (dark).

Different heat treatment temperatures and cooling rates could control the specific phase to be formed. However, the $\beta$ Ti phase is hardly detected, even after $704{ }^{\circ} \mathrm{C}$, in accordance with those XRD patterns highlighted in Fig. 5, where the microstructure is composed of the $\alpha$-Ti phase with no other phase being noted in the XRD pattern. The peaks were denoted by $\alpha$-Ti, since both $\alpha$ and $\alpha$ ' phases have a hexagonal structure with XRD peaks in similar angular positions, where the amount of solute elements in the atomic structure is basically the metallurgical difference between $\alpha$ and $\alpha^{\prime}$ (Ref 25). This finding supports the one presented by both Ter Haar and Becker (Ref 26 ) as well as Kelly (Ref 27), where they found out that the $\alpha$ phase started to dissolute into the $\beta$ phase under equilibrium heating conditions at 707.8 and $705{ }^{\circ} \mathrm{C}$, respectively. Besides, Malinov et al. (Ref 28 ) determined that the $\beta$ phase nucleation starts from $650{ }^{\circ} \mathrm{C}$ to become around $4 \%$ at $700{ }^{\circ} \mathrm{C}$, which is difficult to be observed, while it is around $10 \%$ at $750{ }^{\circ} \mathrm{C}$. However, on the one hand, in the presence of any $\beta$ phase, the amount would be very low and it would be barely detectable, because XRD has a detection limit of approximately $2 \%$ of the sample (Ref 29). On the other hand, the microstructure of the
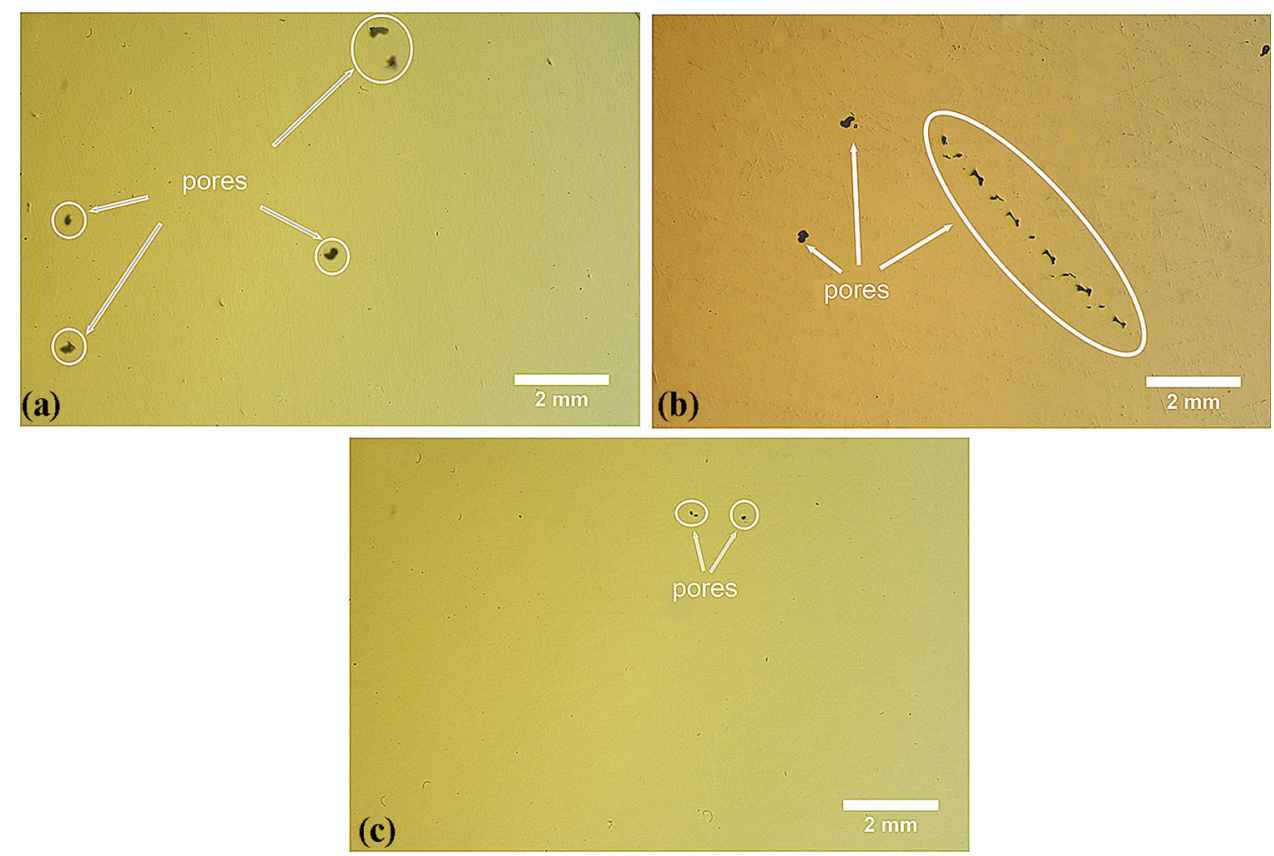

Fig. 3 Optical micrographs showing the pores. (a) Stress-relieved sample, (b) sample with low number of cycles to failure indicated with an arrow in Fig. 2, (c) HIPed sample 

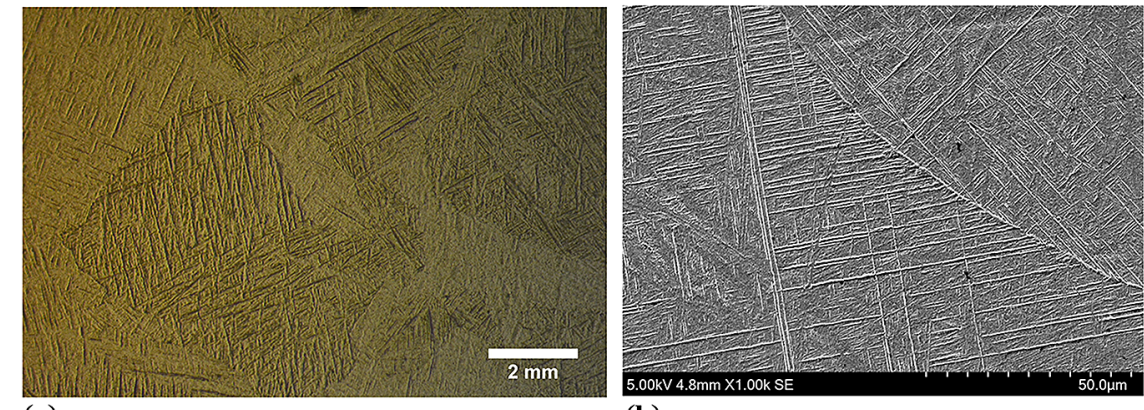

(a)

(b)
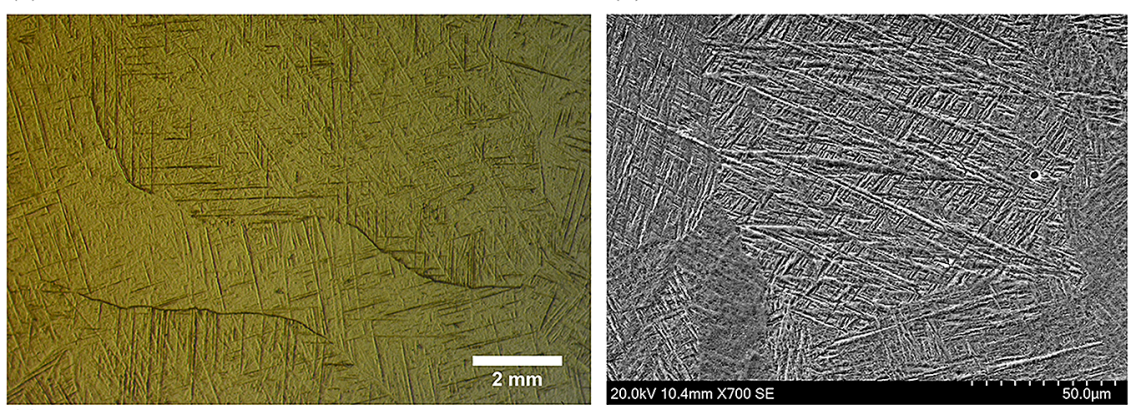

(c)

(d)

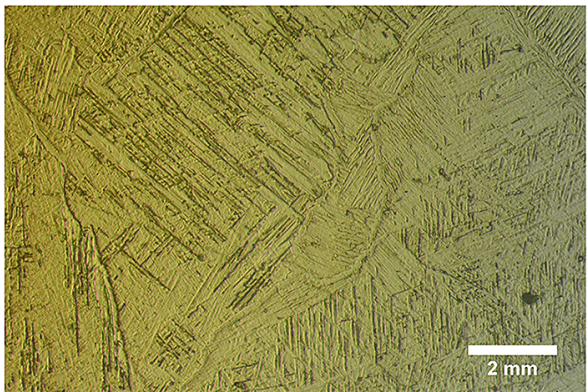

(e)
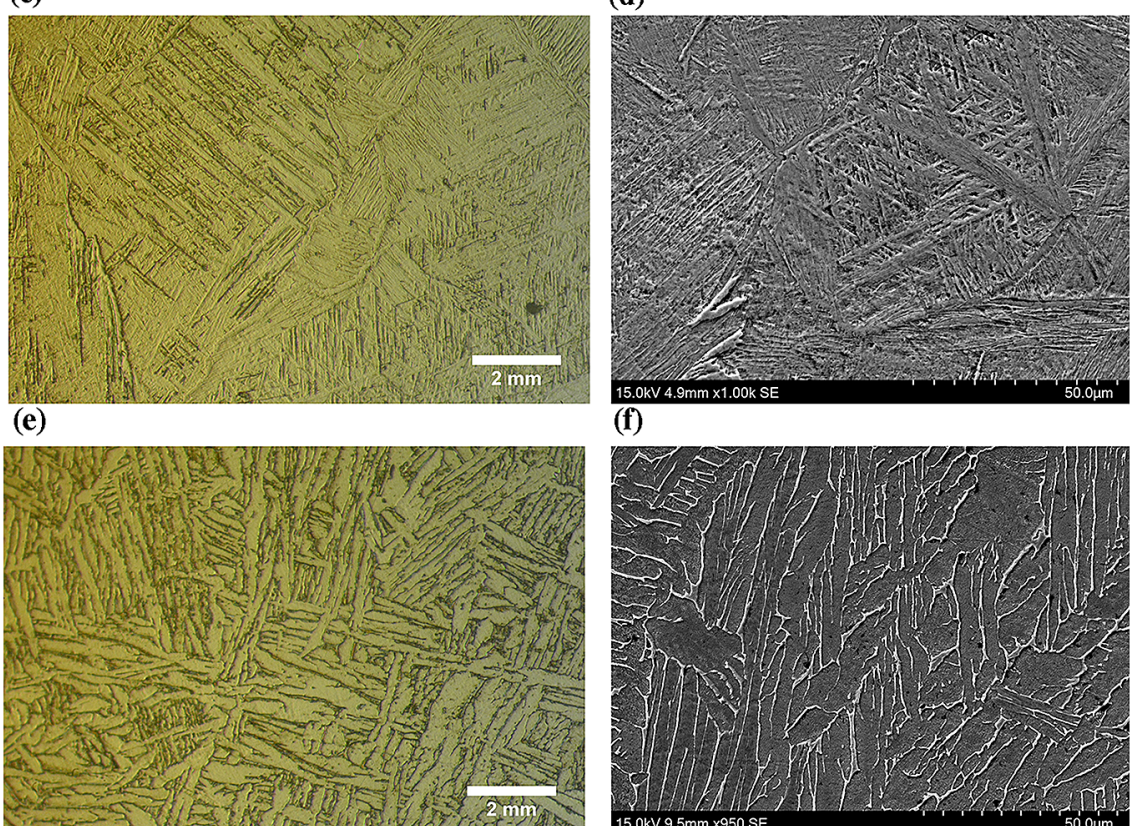

(f)

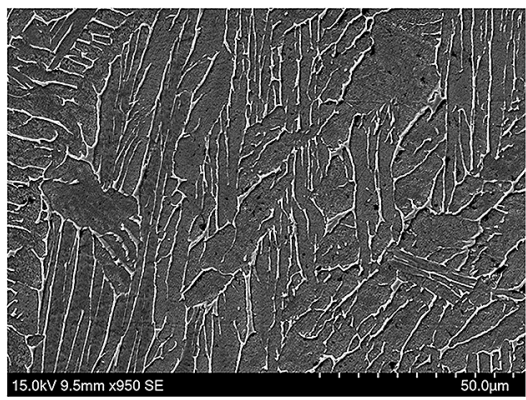

(g)

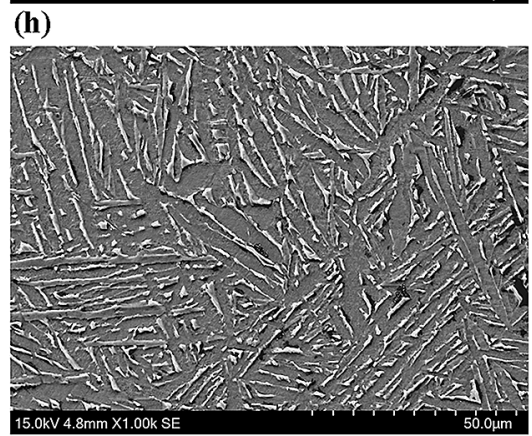

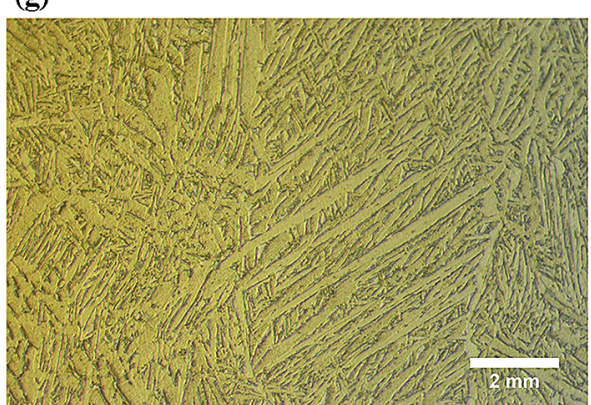

(i) (j)

Fig. $4 \mathrm{OM}$ and SEM images of the microstructure of Ti-6Al-4V produced by SLM after heat treating at different temperatures followed by different cooling rates. (a) and (b) SR at $704{ }^{\circ} \mathrm{C}$, (c) and (d) WQ from $1015{ }^{\circ} \mathrm{C}$, (e) and (f) AC from $1015{ }^{\circ} \mathrm{C}$, (g) and (h) $\mathrm{FC}$ from $1015{ }^{\circ} \mathrm{C}$ and (i) and (j) SR+HIP followed by FC 


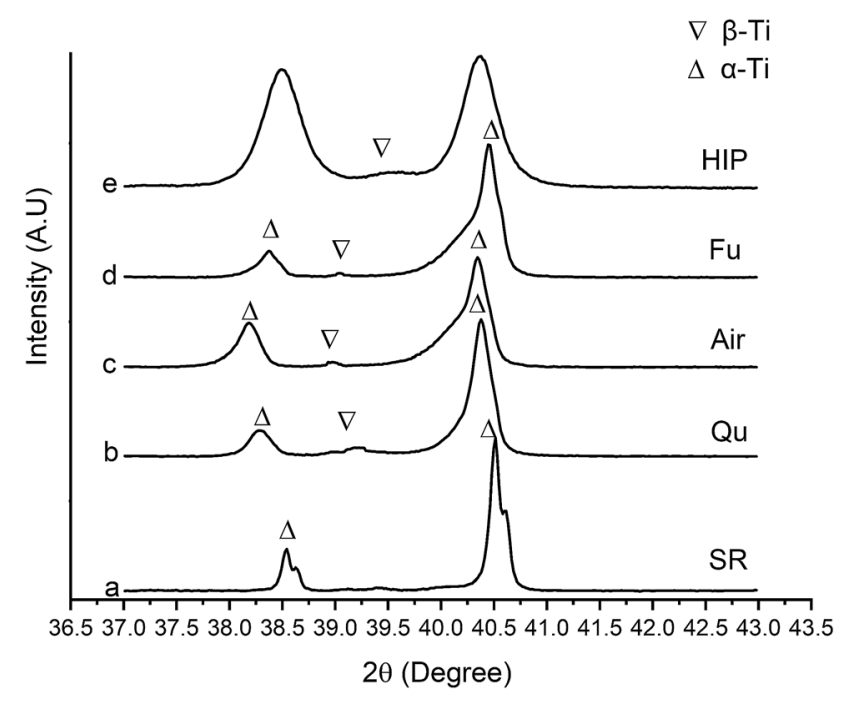

Fig. 5 XRD patterns of SLM samples after different heat treatments. (a) Stress relived, (b) quenched, (c) air-cooled, (d) furnace cooled, and (e) HIPed samples

air and furnace cooled samples comprises of both $\alpha$ and $\beta$ phases. Compared with air-cooling, the XRD peak intensity of the $\beta$ phase is weaker following furnace cooling owing to the low volume fraction of the $\beta$ phase in the alloy at room temperature. Compared with air and furnace cooling, the peak intensity of $\beta$ in quenched samples is higher. This may be attributed to the rapid cooling process from $1015{ }^{\circ} \mathrm{C}(100 \% \beta$ phase), resulting in diffusionless transformation. Accordingly, there is inadequate time for $\alpha$ to form. This results in the formation of the dominating $\alpha^{\prime}$ martensite phase, permitting an additional amount of $\beta$ that remains between the needles compared with the air-cooling process (Fig. 6).

\section{Conclusions}

This study's primary objective was to analyse the microstructure properties of the Ti-6Al-4V alloy fabricated by SLM, following its subjection to diverse heat treatment levels. The main conclusions that can be drawn from the conducted research are as follows:

- There was no significant difference in hardness or microstructure between the top and bottom of each sample before post-heat treatment.

- Only the $\alpha^{\prime}$ martensitic phase can be detected even after stress relieving at $704{ }^{\circ} \mathrm{C}$, whereas noticeable changes occurred with further treatment at $1015^{\circ} \mathrm{C}$ followed by different cooling rates occurred. Slow cooling (furnace) led to a coarse lamellar microstructure of $\alpha+\beta$, while aircooling led to a mixture of $\alpha^{\prime}+\alpha$ with lower hardness compared with those SR samples.

- The sample that had a low number of cycles to failure had cracks and increased porosity on the fracture surface compared to the other samples, which resulted in it failing prematurely during fatigue testing. This necessitates further investigation.

- Furnace and HIP processed samples have lower microhardness and improved fatigue properties. This may be
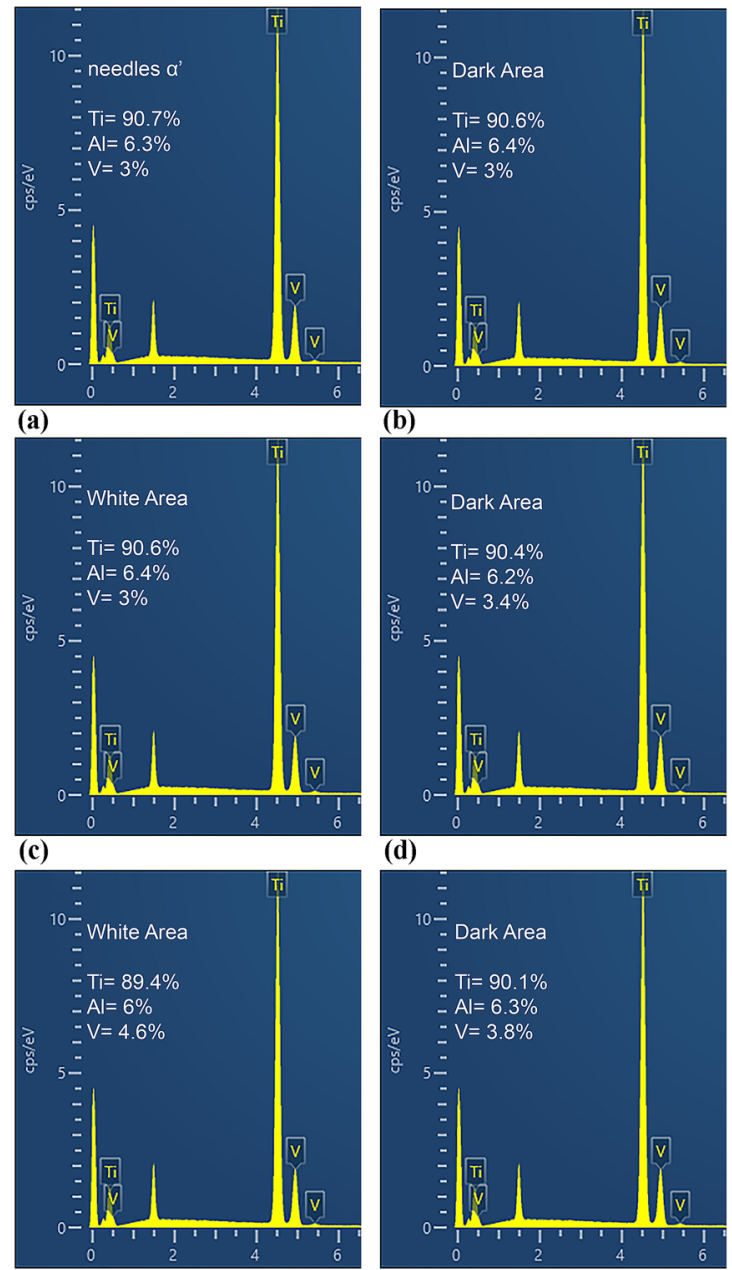

(e)
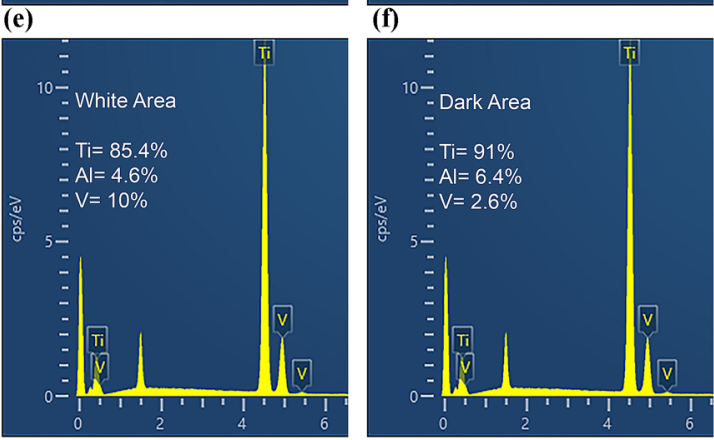

(g)

(h)
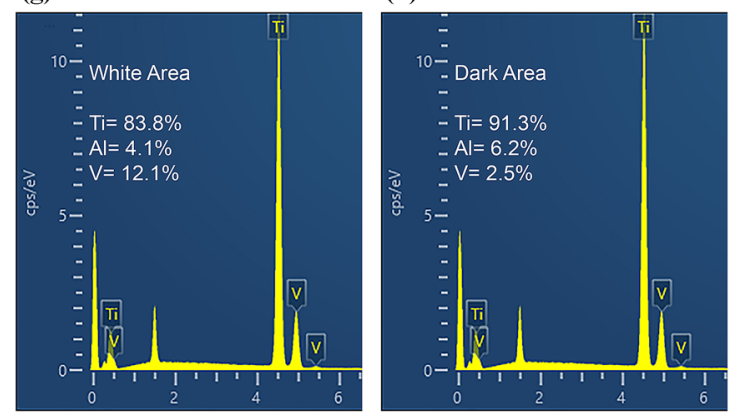

(i)

(j) 
4Fig. 6 EDS spectra and the composition in wt. \% of Ti-6Al-4V samples after different heat treatment. "White" and "Dark" indicated in the figures correspond to the brightness in the SEM images in Fig. 4b, d, f, h, and j. (a) and (b) SR at $704{ }^{\circ} \mathrm{C}$, (c) and (d) WQ from $1015^{\circ} \mathrm{C}$, (e) and (f) AC from $1015^{\circ} \mathrm{C}$, (g) and (h) $\mathrm{FC}$ from $1015^{\circ} \mathrm{C}$ and (i) and (j) SR+HIP followed by $\mathrm{FC}$

explained by the transformation of the needle-shaped $\alpha$ ' to lamellar $\alpha+\beta$, as well as the appearance of a more ductile $\beta$ phase.

\section{Open Access}

This article is licensed under a Creative Commons Attribution 4.0 International License, which permits use, sharing, adaptation, distribution and reproduction in any medium or format, as long as you give appropriate credit to the original author(s) and the source, provide a link to the Creative Commons licence, and indicate if changes were made. The images or other third party material in this article are included in the article's Creative Commons licence, unless indicated otherwise in a credit line to the material. If material is not included in the article's Creative Commons licence and your intended use is not permitted by statutory regulation or exceeds the permitted use, you will need to obtain permission directly from the copyright holder. To view a copy of this licence, visit http://creativecommons.org/licenses/by/4.0/.

\section{References}

1. B. Vrancken, L. Thijs, J.-P. Kruth, and J. Van Humbeeck, Heat Treatment of Ti6Al4V Produced by Selective Laser Melting: Microstructure and Mechanical Properties, J. Alloys Compd., 2012, 541, p 177-185

2. P. Tao, H. Li, B. Huang, Q. Hu, S. Gong, and Q. Xu, Tensile Behavior of Ti-6Al-4V Alloy Fabricated By Selective Laser Melting: Effects of Microstructures and As-Built Surface Quality, China Foundry, 2018, 15(4), p 243-252

3. M. Shunmugavel, "Machinability Studies of Selective Laser Melted Titanium Alloy Ti-6Al-4V," Deakin University; PhD thesis, 2017, n.d

4. T. Childerhouse and M. Jackson, Near Net Shape Manufacture of Titanium Alloy Components From Powder and Wire: A Review Of State-of-the-Art Process Routes, Metals (Basel), 2019, 9(6), p 689

5. X. Tan, Y. Kok, Y.J. Tan, G. Vastola, Q.X. Pei, G. Zhang, Y.-W. Zhang, S.B. Tor, K.F. Leong, and C.K. Chua, An Experimental And Simulation Study on Build Thickness Dependent Microstructure For Electron Beam Melted Ti-6Al-4V, J. Alloys Compd., 2015, 646, p 303-309

6. Q. Yan, B. Chen, N. Kang, X. Lin, S. Lv, K. Kondoh, S. Li, and J.S. Li, Comparison Study on Microstructure and Mechanical Properties of Ti6Al-4V Alloys Fabricated by Powder-Based Selective-Laser-Melting and Sintering Methods, Mater. Charact., 2020, 164, p 110358

7. W. Xu, S. Sun, J. Elambasseril, Q. Liu, M. Brandt, and M. Qian, Ti6Al-4V Additively Manufactured by Selective Laser Melting with Superior Mechanical Properties, JOM, 2015, 67(3), p 668-673

8. J. Mezzetta, "Process-Property Relationships of Ti6Al4V Fabricated through Selective Laser Melting," McGill University; PhD thesis, 2017 , n.d

9. S. Goel, M. Ahlfors, F. Bahbou, and S. Joshi, Effect of Different PostTreatments on the Microstructure of EBM-built Alloy 718, J. Mater. Eng. Perform., 2019, 28(2), p 673-680. https://doi.org/10.1007/s1166 5-018-3712-0

10. H. Ali, L. Ma, H. Ghadbeigi, and K. Mumtaz, In-Situ Residual Stress Reduction, Martensitic Decomposition and Mechanical Properties
Enhancement Through High Temperature Powder Bed Pre-Heating of Selective Laser Melted Ti6Al4V, Mater. Sci. Eng. A, 2017, 695, p 211-220

11. H. Ali, H. Ghadbeigi, F. Hosseinzadeh, J. Oliveira, and K. Mumtaz, Effect of Pre-Emptive In Situ Parameter Modification on Residual Stress Distributions Within Selective Laser-Melted Ti6A14V Components, Int. J. Adv. Manuf. Technol., 2019, 103(9-12), p 4467-4479

12. D. Agius, K.I. Kourousis, and C. Wallbrink, A Review of the As-Built Slm Ti-6al-4v Mechanical Properties Towards Achieving Fatigue Resistant Designs, Metals (Basel), 2018, 8(1), p 75

13. M. Simonelli, Y.Y. Tse, and C. Tuck, The Formation of A + B Microstructure In as-Fabricated Selective Laser Melting Of Ti-6Al-4V, J. Mater. Res., 2014, 29(17), p 2028-2035

14. G. Nicoletto, S. Maisano, M. Antolotti, and F. Dall'aglio, Influence of Post Fabrication Heat Treatments on the Fatigue Behavior of Ti-6Al4V Produced by Selective Laser Melting, Procedia Struct Integr, 2017, 7, p $133-140$

15. S. Wang, "In TMS 2018 147th Annual Meeting and Exhibition Supplemental Proceedings, Pp.13-20," Springer International Publishing, Cham, 2018

16. M. Shiomi, K. Osakada, K. Nakamura, T. Yamashita, and F. Abe, Residual Stress Within Metallic Model Made by Selective Laser Melting Process, CIRP Ann., 2004, 53(1), p 195-198

17. T. Becker, M. Van Rooyen, and D. Dimitrov, Heat Treatment of Ti-6Al4V Produced by Lasercusing, South African J. Ind. Eng., 2015, 26(2), p 93-103

18. A.M. Asiri and A. Mohammad, Applications of Nanocomposite Materials in Dentistry, Woodhead Publishing, 2018

19. R. Radzali, M.Z. Zakariah, A. Mahmood, A.F.A. Rahim, Z. Hassan, and Y. Yusof, The Effect of Ecthing Duration on Structural Properties of Porous Si Fabricated by a New Two-Steps Alternating Current Photo-Assisted Electrochemical Etching (ACPEC) Technique for MSM Photodetector, AIP Conf. Proceedings, vol. 1875, 020003. AIP Publ. LLC; (2017)., AIP Publishing LLC, n.d

20. J. Mezzetta, J.-P. Choi, J. Milligan, J. Danovitch, N. Chekir, A. BoisBrochu, Y.F. Zhao, and M. Brochu, Microstructure-Properties Relationships of Ti-6Al-4V Parts Fabricated by Selective Laser Melting, Int. J. Precis. Eng. Manuf. Technol., 2018, 5(5), p 605-612

21. M.N. Gussev, N. Sridharan, Z. Thompson, K.A. Terrani, and S.S. Babu, Influence of Hot Isostatic Pressing on the Performance of Aluminum Alloy Fabricated by Ultrasonic Additive Manufacturing, Scr. Mater, 2018, 145, p 33-36

22. M. Neikter, A. Huang, and X. Wu, Microstructural Characterization of Binary Microstructure Pattern in Selective Laser-Melted Ti-6Al-4V, Int. J. Adv. Manuf. Technol., 2019, 104(1-4), p 1381-1391

23. S. Gorsse, C. Hutchinson, M. Gouné, and R. Banerjee, Additive Manufacturing of Metals: A Brief Review of the Characteristic Microstructures and Properties of Steels, Ti-6al-4v and High-Entropy Alloys, Sci. Technol. Adv. Mater., 2017, 18(1), p 584-610

24. T. Ahmed and H.J. Rack, Phase Transformations During Cooling in $\mathrm{A}+$ $\beta$ Titanium Alloys, Mater. Sci. Eng. A, 1998, 243(1-2), p 206-211

25. X. Zhao, S. Li, M. Zhang, Y. Liu, T.B. Sercombe, S. Wang, Y. Hao, R. Yang, and L.E. Murr, Comparison of the Microstructures and Mechanical Properties of Ti-6Al-4V Fabricated by Selective Laser Melting and Electron Beam Melting, Mater. Des., 2016, 95, p 21-31

26. G.M. Ter Haar and T.H. Becker, Selective Laser Melting Produced Ti6al-4v: Post-Process Heat Treatments to Achieve Superior Tensile Properties, Materials (Basel), 2018, 11(1), p 146

27. S.M. Kelly, "Thermal and Microstructure Modeling of Metal Deposition Processes with Application to Ti-6Al-4V," Virginia Tech; PhD thesis, 2004, n.d

28. S. Malinov, W. Sha, Z. Guo, C.C. Tang, and A.E. Long, Synchrotron X-ray Diffraction Study of the Phase Transformations in Titanium Alloys, Mater. Charact., 2002, 48(4), p 279-295

29. A.A. Bunaciu, E.G. UdriŞTioiu, and H.Y. Aboul-Enein, X-ray Diffraction: Instrumentation and Applications, Crit. Rev. Anal. Chem., 2015, 45(4), p 289-299

Publisher's Note Springer Nature remains neutral with regard to jurisdictional claims in published maps and institutional affiliations. 